\title{
Docência em EJA no IFG: Extensão no Contexto da Pandemia Covid19
}

\author{
Teaching in Young And Adult Education in the IFG: \\ Extension in the context of Pandemic Covid19
}

\section{Trabajo Didáctico sobre EJA en IFG: Extensión en el contexto de la Pandemia Covid19}

\author{
(iD) \\ Josué Vidal Pereira \\ Instituto Federal de Goiás \\ (iD) Sebastião Cláudio Barbosa
}

\section{1}

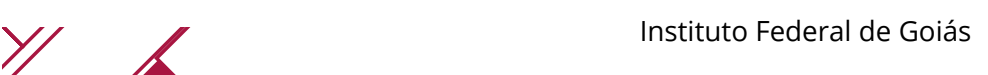

Resumo: Este texto tem como objeto o relato de experiência de ação de Extensão, desenvolvida por dois professores do Instituto Federal de Goiás. Trata-se de um minicurso de Formação Continuada em docência na Educação de Jovens e Adultos, em vista da alta demanda por formação na área. 0 minicurso foi desenvolvido em 40 horas de atividades síncronas e assíncronas, contemplando os elementos mais essenciais para a docência na EJA. As atividades foram realizadas por meio de debates e diálogos entre docentes e cursistas, por meio do qual foi socializado os conteúdos dos textos previamente disponibilizados, articulando-os com as experiências dos próprios participantes. Do total de 40 inscritos, 30 participantes iniciaram as atividades e 19 foram certificados. A ação foi considerada muito exi- 
tosa, apontando para a necessidade do fortalecimento das ações de extensão do IFG, dado o seu papel social de oferta pública e gratuita de educação com qualidade socialmente referenciada.

Palavras-chave: Docência em EJA. Extensão em EJA. Formação Continuada na EJA.

Abstract: This text has as its object the report of experience of action of Extension, developed by two professors of the Federal Institute of Goiás. It is a mini-course of Continuing Education in teaching in Youth and Adult Education, in view of the high demand for training in area. The short course was developed in 40 hours of synchronous and asynchronous activities, covering the most essential elements for teaching at YAE. The activities were carried out through debates and dialogues between teachers and course participants, through which the contents of the texts previously made available was socialized, articulating them with the experiences of the participants themselves. Of the total of 40 enrolled, 30 participants started the activities and 19 were certified. The action was considered very successful, pointing to the need to strengthen IFG's extension actions, given its social role as a public and free offer of education with socially referenced quality.

Keywords: EJA teaching. Extension in EJA. Continuing Education at EJA.

Resumen: Este texto tiene como objeto el relato de experiencia de la acción de Extensión, elaborado por dos profesores del Instituto Federal de Goiás. Se trata de un minicurso de Educación Continuada en la docencia en Educación de Jóvenes y Adultos, ante la alta demanda de formación en este campo de la educación. El curso corto se desarrolló en 40 horas de actividades sincrónicas y asincrónicas, cubriendo los elementos más esenciales para la docencia en EJA. Las actividades se realizaron a través de debates y diálogos 


\section{Introdução}

No contexto desencadeado pela propagação do Novo Coronavíurs, que resulta na declaração oficial da Pandemia Global da Covid19 pela Organização Mundial da Saúde em 11 de março de 2020, as Instituições de Ensino Superior brasileiras (IES), forçadas ao movimento de paralisação compulsória da maior parte de suas atividades, se viram diante de um cenário dramático digno de um filme de ficção científica. As contingências decorrentes do isolamento e demais restrições forçadas pela propagação de um vírus com alto potencial de letalidade - de março a outubro de 2020, mais de 155.000 mortos - impactou de modo severo o trabalho desenvolvido no âmbito das Universidades, Institutos Federais de Educação, Ciência e Tecnologia, faculdades privadas e demais instituições educacionais do país, remetendo-nos para uma assertiva de Marx e Engels em "O manifesto comunista" quando afirmam que “(...) tudo que é sólido se desmancha no ar" (2008, p. 15).

As IES ligadas ao capital, com foco quase exclusivamente na dimensão do Ensino e com inexpressiva atuação na extensão e na pesquisa, as quais já há algumas décadas atuam, reitera-se, dentro de uma lógica do que Bauer (2008) denomina como quase-mercado, não vacilaram em generalizar o uso das ferramentas de Educação à Distância (EAD) como forma de em alguma medida contornar ou minimizar os efeitos do fechamento abrupto de seus espaços físicos, o que evidenciaria drástica redução em suas receitas. Convém notar que na conjuntura anterior à crise derivada da Pandemia, e do recente processo de oligopolização do Ensino Superior Privado, já se fazia notar a disseminação indiscriminada do uso de ferramentas EAD, como forma de aumento de rentabilidade - uma vez que os grandes grupos universitários estão presentes na Bolsa de Valores, inclusive capitalizando-se (Carvalho, 
Docência em Eja no Ifg: Extensão no Contexto da Pandemia Covid19 Josué Vidal Pereira - Sebastião Cláudio Barbosa , et al...

2013), em razão da grave crise de financiamento das IES Públicas, sentidas sobretudo a partir do Golpe jurídico-empresarial-midiático de 2016.

Quanto às Instituições Públicas, sejam Universidades ou Institutos Federais, cuja lógica de funcionamento são geralmente determinadas pelo interesse público e por princípios como igualdade de condições de acesso e permanência, se viram sob o enorme dilema: esperar o término da Pandemia para a volta à normalidade da vida acadêmica ou abrirem-se para a generalização de um modelo de Ensino Remoto Emergencial - denominação adotada no Instituto Federal de Goiás, assumindo uma gama de riscos, tais como: no curto prazo, a exclusão de parcelas mais empobrecidas de seus estudantes, cujas condições de permanência ficam dificultadas pela ausência de meios necessários como infraestrutura de internet banda larga e aparelhos de comunicação, ambiente habitacional adequado para estudos entre outros; e no longo prazo, existe a perspectiva de que novas reformas governamentais se utilizem de tais experiências para incrementar ainda mais os níveis de precarização do trabalho docente e do próprio sucateamento das IES públicas.

Na verdade, desde a década de 1990, tem havido por parte dos "negociantes da educação" uma tentativa de submetê-la aos pressupostos da "economia de serviços". Isso, como já denunciava Freitas (2012), é a expressão mais clara do neoliberalismo, uma vez que desconstrói a educação como a alma da nação e do seu desenvolvimento soberano. É, de fato, uma tentativa de golpe na soberania nacional, impondo critérios do "livre mercado", a partir da imposição de valores de essência empresarial capitalista privatista, como a competição meritocrática e a ideia de concorrência, inculcadas como fundamentos "inovadores" e "democráticos". Além disso, como consequência desse movimento de gestão em- 
Docência em Eja no Ifg: Extensão no Contexto da Pandemia Covid19 Josué Vidal Pereira - Sebastião Cláudio Barbosa , et al...

presarial na educação, há, sobretudo a partir de 2016 - e a aprovação da Base Nacional Comum Curricular (BNCC), é mais uma demonstração desse fato -, a tentativa de criar padrões de medição de eficiência dos "serviços" prestados, por meio de ranqueamento e exames nacionais submetidos a interesses hegemônicos de organismos internacionais, como, por exemplo, o Banco Mundial.

Freitas (2012, p. 383) explica esse movimento empresarial como "neotecnicismo", que, segundo ele, "se estrutura em torno a três grandes categorias: responsabilização, meritocracia e privatização. No centro, está a ideia do controle dos processos, para garantir certos resultados definidos a priori como "standards", medidos em testes padronizados". O autor continua, e explica como se dá o sistema de responsabilização como transferência de valores e responsabilidades para docentes, escolas e indivíduos. Tal sistema envolveria três elementos: "testes para os estudantes, divulgação pública do desempenho da escola e recompensas e sanções". Segundo o autor,

[...] as recompensas e sanções compõem o caráter meritocrático do sistema, mas não só, já que a própria divulgação pública dos resultados da escola constitui em si mesma uma exposição pública que envolve alguma recompensa ou sanção públicas. A meritocracia é uma categoria, portanto, que perpassa a responsabilização. (Freitas, 2012, p. 383).

Vê-se, portanto, em curso processos que visam precarizar as relações trabalhistas, estabelecendo a terceirização e a informalidade, no âmbito do serviço público e, consequentemente na educação. Busca-se, dessa forma, isolar a educação dos seus pressupostos e amarrilhos sociais, assim como do projeto de desenvolvimento da nação, vendendo-a como uma mercadoria como 
Docência em Eja no Ifg: Extensão no Contexto da Pandemia Covid19 Josué Vidal Pereira - Sebastião Cláudio Barbosa , et al...

outra qualquer. Dessa forma, responsabiliza-se professores e indivíduos pelo "baixo rendimento", ao mesmo tempo em que deprecia o campo educacional, submetendo-o à máxima "pagando bem, que mal tem?". Significa dizer que, reduzindo a educação a um "negócio" quem puder pagar terá um serviço educacional condizente; quem não puder pagar, terá a assistência do Estado, na forma do paternalismo, do assistencialismo e de políticas compensatórias.

O objetivo deste artigo é relatar a experiência de uma ação de extensão desenvolvida por dois servidores do Instituto Federal de Goiás, doravante IFG - ambos autores deste texto, no contexto da suspensão das atividades de Ensino da Instituição que ocorreu entre 16 março a 30 de agosto de 2020. Deve-se pontuar que as atividades dos servidores não foram paralisadas durante $o$ período supracitado. Além da manutenção de atividades rotineiras de atribuições do segmento docente, tais como reuniões de comissões, conselhos e colegiados e outros, que continuaram a ocorrer utilizando-se a mediação de ferramentas como webconferências, também foram desencadeadas diversas ações de extensão em todos os campi, tais como oficinas, cursos, minicursos, como também na área da cultura do esporte e lazer.

\section{Formação Continuada em Docência na Educação de Jovens e Adultos}

A ação de extensão relatada neste artigo, trata de um curso de Formação Continuada em Docência na modalidade de Educação de Jovens e Adultos (EJA). A opção por uma oferta de Projeto de Extensão no campo da EJA, relaciona-se primeiramente à ligação dos autores com o campo, mas principalmente com a constatação da alta demanda por formação na área, uma vez que historica- 
Docência em Eja no Ifg: Extensão no Contexto da Pandemia Covid19 Josué Vidal Pereira - Sebastião Cláudio Barbosa , et al...

mente a modalidade padece da negligência das políticas de formação de educadores para a área. Embora a educação de adultos no Brasil tenha ocupado lugar de destaque nas políticas educacionais sobretudo a partir da Era Vargas, conforme ressalta Ventura (2006), somente no final do século XX ela ganha status de modalidade educacional a partir da promulgação da Lei de Diretrizes e Bases da Educação Nacional - LDBEN n 9.394, em que pese um tratamento um tanto superficial, ocupando apenas dois artigos da referida lei, totalizando apenas 156 palavras, quantitativo similar ao do resumo deste trabalho.

O vácuo de políticas de formação para a docência na EJA se relaciona de modo mais geral à própria identidade da modalidade, associada pelo público em geral como processos educativos precários, frequentemente realizados por meio de cursos rápidos e pragmáticos, guardando certa identificação com o antigo supletivo e as determinações da Lei 5.692/71 que propagandeou, durante a Ditadura Civil-Militar (1964-1985), a "teoria do capital humano" e estabeleceu "planos emergenciais" para a educação. O discurso era de "salvação", mas a prática era (é!) de aligeiramento e desconstrução do sentido emancipatório da educação. Ao tratar do conjunto das políticas educacionais para esse público, que em resumo é a classe trabalhadora jovem e adulta, na primeira década do século XX, Rummert (2007) enfatiza que em seu conjunto os programas executados trazem forte conteúdo ideológico, tangenciando as causas estruturais da exclusão de grande parte da população ao acesso a uma escolarização efetiva, de direito. Desse modo, diz a autora,

“(...) são oferecidas possibilidades de elevação de escolaridade com caráter precário e aligeirado, porém anunciadas como portadoras potenciais de inclusão. Trata-se, assim, sobre- tudo, 
de atuar de forma urgente para controlar disfunções de um sistema que, por sua origem estrutural, continuará a gerar, cada vez mais, demandantes de novas medidas de caráter emergencial.

Deve-se assinalar que, em que pese todo o descaso do Estado e da sociedade traduzido no lugar marginal das políticas de EJA, verificou-se na década de 2000 avanços importantes na modalidade, a exemplo da criação do Programa Nacional de Integração da Educação Básica com a Educação Profissional da Modalidade de Educação de Jovens e Adultos (Proeja), por meio do Decreto 5.840 de 13 de julho de 2006, como também a inclusão das matrículas da EJA no financiamento público por meio da política do Fundo de Manutenção e Desenvolvimento da Educação Básica e Valorização dos Profissionais da Educação, através da lei n 11.494 de 20 de junho de 2007. Contudo, a referida lei, além de limitar em até 15\% os recursos para a modalidade EJA, depreciava os fatores de ponderação do cálculo para o financiamento desta modalidade em relação a outros níveis da Educação Básica. A título de exemplo, o fator de ponderação atribuído à EJA, segundo Bueno e Pergher (2017), no ano de 2016, foi de 0,80, enquanto o Ensino Médio urbano registrou 1,25.

Tem-se, portanto, que a garantia de inclusão da modalidade numa Política de Estado para o financiamento da educação, teria potencial de indução do número de matrículas em vista da expressiva parcela da população com baixos níveis de escolarização e ainda o mais baixo percentual dos que logravam a conclusão do Ensino Médio. No entanto, tal expectativa se converteu em enorme frustração. É o que aponta o Censo oficial da educação nacional. A título de ilustração do que afirmamos, segundo o Censo da Educação Básica do Instituto Nacional de Estudos e Pesquisas Educacionais Anísio Teixeira (INEP, 2008), foram registradas no 
Docência em Eja no Ifg: Extensão no Contexto da Pandemia Covid19 Josué Vidal Pereira - Sebastião Cláudio Barbosa , et al...

ano 2007 um total de 4.940.165 matrículas na EJA. Em 2013, foram 3.773.670 matriculados (INEP, 2014) e no ano de 2018 um total de 3.545.988 matrículas (INEP, 2019), com uma retração de aproximadamente 1,4 milhões de matrículas em 11 anos.

E o que se percebe é que tal retração de matrículas não representa redução de demanda, mas, sim, descaso com a modalidade e suas especificidades. Pois, é sabido que a demanda em EJA, apesar de gigantesca, é arredia, traumatizada, não "bate na porta para entrar" como se diz comumente nas instâncias que lutam e representam a modalidade, como, por exemplo, os Fóruns de EJA. Ela precisa - para se estabelecer, permanecer e ter êxito, de políticas consistentes e interessadas, que compreendam seus princípios e características basilares, incentivem e criem mecanismos amorosos de continuidade.

Não obstante, o discurso patronal do suposto "apagão de mão de obra qualificada", sabe-se que há um grande desencantamento em relação à escola enquanto instituição integradora da sociedade, como afirma Gentili (1998), para quem a escola já não consegue cumprir a promessa de integração via mercado de trabalho. Ademais, o mercado de trabalho é frio e calculista, se mostrando um péssimo conselheiro para as demandas educacionais. Por isso, a despeito de toda uma elaboração ideológica de cunho neoliberal, que busca deslocar para a escola a responsabilidade pela criação de postos de trabalho, a realidade tem mostrado certa desesperança com o sistema escolar, sobretudo no que diz respeito a determinados tipos de ofertas precarizadas, que não se alinham com as demandas de certos setores - sobretudo aqueles com uso intensivo de tecnologias de informação e comunicação, os quais exigem cada vez mais elevados níveis de escolarização, que, aliás, o mercado, por si só, não pretende promover e nem se sensibilizar, ainda mais quando ele é entendido como fim e não 
Docência em Eja no Ifg: Extensão no Contexto da Pandemia Covid19 Josué Vidal Pereira - Sebastião Cláudio Barbosa , et al...

como meio do desenvolvimento local, regional e nacional. Nesse sentido, a perspectiva formativa via demandas do mercado está baseada na reprodutibilidade técnica e não na inventividade que a produção de novas tecnologias exige.

O que pretendemos problematizar neste artigo, trata-se precisamente do fato de que a despeito de todos os fatores de cunho socioeconômico, portanto estruturais, que determinam o impedimento do acesso de milhões de brasileiros ao sistema educacional em nível de educação básica, tem-se que parte significativa dos poucos que conseguem adentrar às salas de aulas, conseguem permanecer na escola e ter êxito na conclusão das respectivas etapas dos níveis fundamental e médio. Inferimos, e muitos estudos o demonstram - a exemplo de Pereira (2011), que há uma gama de fatores internos aos espaços escolares que interferem de modo decisivo no abandono, na retenção e, portanto, no fracasso escolar dos Adolescentes, Jovens e Adultos trabalhadores.

A ação de extensão relatada neste trabalho, teve como foco especificamente a formação docente para a atuação na modalidade Educação de Jovens e Adultos. A ausência desse "perfil" docente adequado se constitui, na nossa perspectiva, em fator intraescolar fundamental para explicar parte das altas taxas de evasão verificadas na modalidade. Percebíamos de antemão que se trata de uma área com alto nível de demanda pelos profissionais da educação, uma vez que a formação de professores no Brasil tem historicamente quase que ignorado tal demanda. Nossa percepção foi corroborada pela volumosa demanda registrada no retorno do processo de divulgação do curso ofertado. É sabido, contudo, que com a força e pressão causadas pela ideologia do produtivismo, "todo mundo se inscreve em tudo que aparece hoje em dia". Há nesse sentido, muitas vezes, um número muito díspar em relação a quem, de fato, fará o curso em que está inscrito. É 
Docência em Eja no Ifg: Extensão no Contexto da Pandemia Covid19 Josué Vidal Pereira - Sebastião Cláudio Barbosa , et al...

comum, hoje em dia, depoimentos do tipo: "me inscrevo em tudo, depois vou ver o que, vou fazer, de fato". Mesmo assim, este curso que oferecemos superou a todas as expectativas de inscrição e, no final, conseguiu-se manter com um número, para nós, surpreendente, por tudo que já foi exposto acerca dessa "metafísica atual dos costumes", no dizer kanteano.

Nesse sentido, o projeto intitulado "Formação Continuada em Docência na EJA" foi elaborado tendo em vista alcançar o público constituído por professores da Educação Básica de todas as redes, públicas e privadas. Foram ofertadas 40 vagas a serem preenchidas, tendo como único critério de seleção a ordem de inscrição (mais 10 vagas por lista de espera) no formulário disponível no sítio eletrônico do Instituto Federal de Goiás. Além das páginas oficiais da instituição (figura 1), foram elaborados banners para compartilhamento por aplicativo de mensagens e divulgados em diversos grupos de professores, fóruns e outras entidades ligadas à Educação de Jovens e Adultos.

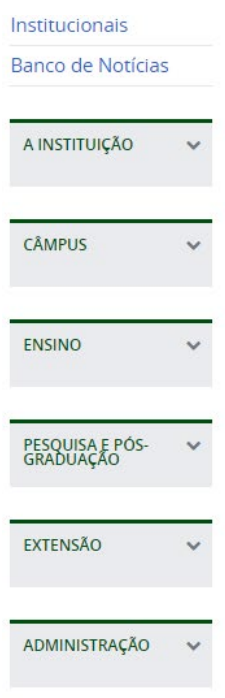

Estão disponíveis 40 vagas, sendo 10 suplentes, destinadas a professores das redes pública e privada, além de servidores do IFG

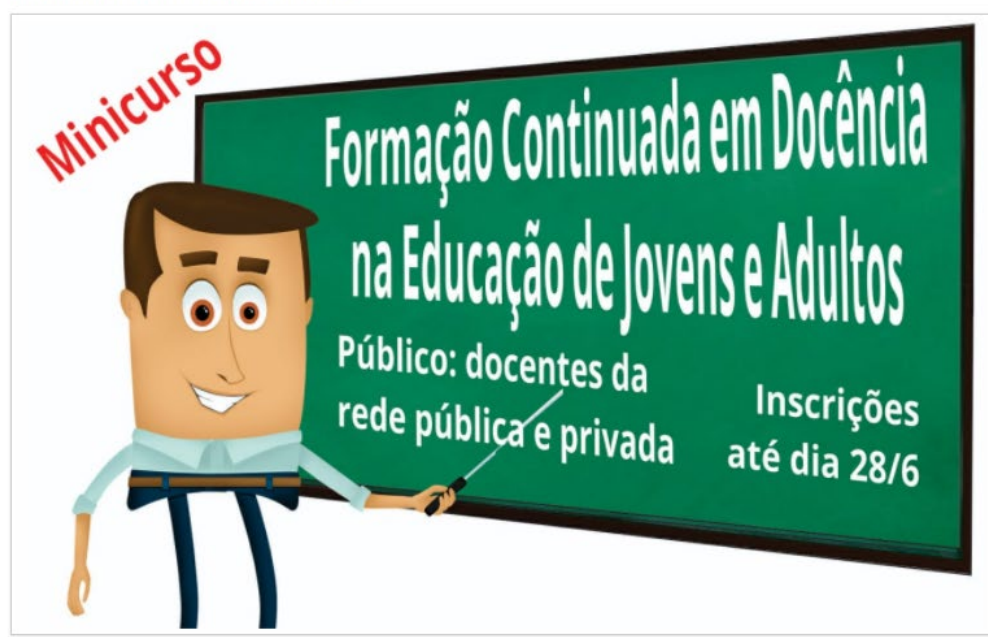

Figura 1: divulgação institucional de ação de extensão Fonte: print de divulgação no sítio eletrônico do IFG 
No processo oficial de divulgação, foi informado que as inscrições ficariam disponíveis entre os dias 18 e 28 de junho de 2020. No entanto, de modo não tão surpreendente, devido ao já explicado acerca da demanda, mas muito surpreendente para nós, proponentes, em menos de 20 horas de disponibilidade do formulário de inscrição online (ferramenta Google formulários), recebemos 209 inscrições de profissionais da educação interessados na realização do minicurso. Identificamos entre os interessados, a maioria, professores residentes em Goiânia e Região Metropolitana, mas também educadores de outras cidades do Estado e mesmo de outros Estados. Desse modo fomos forçados à suspensão das inscrições, dado que não teríamos capacidade de atender toda a demanda apresentada. Sabíamos de antemão que, como já explicado anteriormente, grande número de inscrições não significa, por si só, grande número de participantes ativos e de concluintes, pois muitos desistem por motivos vários: choque de horário com outras atividades, decepção com o curso ("não era bem isso que eu queria"), cansaço de sobrecarga de trabalho, como também problemas de conexão coma internet, entre outros.

No ato da inscrição o requerente deveria, além de informar dados pessoais básicos como nome, telefone de contato e endereço eletrônico, também responder duas questões acerca do seu perfil, tais como instituição e/ou rede ao qual está vinculado como também a área de conhecimento em que atua. O próprio sistema de inscrições gerou automaticamente em forma de gráfico o resultado do levantamento, conforme se apresenta abaixo, possibilitando deste modo, a verificação do perfil dos demandantes da formação continuada em tela. 
Docência em Eja no Ifg: Extensão no Contexto da Pandemia Covid19 Josué Vidal Pereira - Sebastião Cláudio Barbosa , et al...

Qual a sua instituição/rede de vinculo?

209 respostas

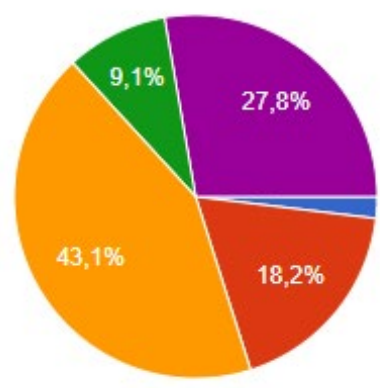

Servidor IFG

Prefeitura de Goiânia

Rede Estadual de Ensino

Rede Privada

Outro

Gráfico 1: perfil de vínculo institucional dos demandantes do minicurso

Fonte: gerado pelo Google Formulários com base nas informações das inscrições

Depreende-se do gráfico 1, que a maioria dos interessados na ação de extensão, ou seja 90,9\% são pertencentes às redes públicas de educação, com destaque para a Rede Estadual de Goiás, que representou quase a metade das inscrições. Deve-se ressaltar que são nas redes públicas onde ocorrem as ofertas regulares de cursos de EJA, em que pese os obstáculos enfrentados pelas escolas e professores, dado o descaso histórico do governo estadual com esta modalidade. Por outro lado, sabe-se que há uma tendência de que os cursos de EJA ofertados nas redes privadas sejam reduzidos praticamente ao que a legislação denomina como supletivo, ou seja, uma certificação baseada nas experiências e conhecimentos adquiridos pelos indivíduos no contexto extraescolar. O gráfico 2 apresenta o perfil dos demandantes em relação vínculo à área de conhecimento. 
Docência em Eja no Ifg: Extensão no Contexto da Pandemia Covid19 Josué Vidal Pereira - Sebastião Cláudio Barbosa , et al...

A qual área de conhecimento está vinculado?

209 respostas

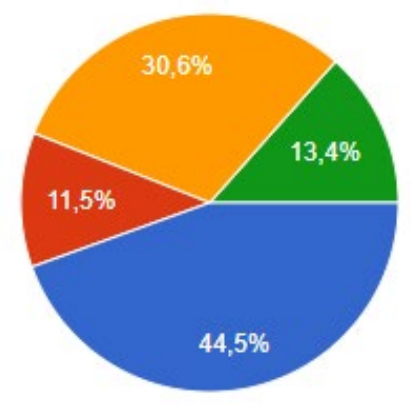

Ciências Humanas

Ciências da Natureza

Linguagens e Artes

Matemática

Gráfico 2: vínculo do demandante do minicurso em relação às áreas do conhecimento Fonte: gerado pelo Google Formulários com base nas informações das inscrições

A segunda questão levantada no breve questionário de inscrição diz respeito ao pertencimento do educador em relação à área do conhecimento ao qual está vinculado. Verificou-se que $75 \%$ dos interessados pertencem às áreas de Ciências Humanas e Linguagens e Artes. A experiência de atuação na área da EJA nos mostra que parece existir maior compreensão dos profissionais destas áreas em relação às demandas específicas para a formação em Educação de Jovens e Adultos e mesmo em relação à necessidade de uma formação pedagógica sólida para atuar na educação em geral.

A elaboração da proposta do minicurso de extensão "Formação Continuada em Docência na EJA" considerou necessário contemplar - em que pese o formato de um curso de baixa carga horária, as várias dimensões que constituem o fazer docente na modalidade Educação de Jovens e Adultos. Nesse sentido, o requerente era informado ainda no formulário de matrícula, sobre os elementos que constituiriam a ementa do minicurso, conforme se observa no quadro 1. 
Docência em Eja no Ifg: Extensão no Contexto da Pandemia Covid19 Josué Vidal Pereira • Sebastião Cláudio Barbosa , et al...

\begin{tabular}{|l|l|}
\hline Data da Atividade & Conteúdo \\
\hline $30 / 06 / 2020$ & $\begin{array}{l}\text { Apresentação e discussão do programa e dos } \\
\text { materiais indicados para estudo }\end{array}$ \\
\hline $05 / 08 / 2020$ & A história da EJA no Brasil: idas e vindas \\
\hline $12 / 08 / 2020$ & A história da EJA no Brasil: parte final \\
\hline $19 / 08 / 2020$ & Políticas para a EJA nas últimas décadas \\
\hline $26 / 08 / 2020$ & $\begin{array}{l}\text { O financiamento da Educação Básica no Brasil } \\
\text { parte I }\end{array}$ \\
\hline $02 / 09 / 2020$ & $\begin{array}{l}\text { Aspectos pedagógicos da docência em EJA: } \\
\text { parte Il }\end{array}$ \\
\hline $09 / 09 / 2020$ & $\begin{array}{l}\text { A EJA e o “nenhum a menos": entre a ética e a } \\
\text { moral }\end{array}$ \\
\hline $16 / 09 / 2020$ & $\begin{array}{l}\text { A EJA e a necessidade do perfil docente: mito } \\
\text { ou realidade? }\end{array}$ \\
\hline $23 / 09 / 2020$ & $\begin{array}{l}\text { Debate final: E aí: valeu a pena estar nesta } \\
\text { formação? }\end{array}$ \\
\hline
\end{tabular}

Quadro 1: Ementa do minicurso apresentada aos demandantes no ato da inscrição Fonte: elaborado pelos autores com informações do formulário de inscrição

Conforme se verifica no quadro 1, os docentes inscritos para realizar a formação continuada, considerando-se os primeiros 40 inscritos, mais as próximas 10 inscrições reservas (que assumiriam a vaga se houvesse desistência entre os primeiros 40 inscritos), tiveram a possibilidade de acessar elementos importantes do que constitui a área de estudos da Educação de Jovens e Adultos. Foram disponibilizados previamente textos e outros materiais selecionados pelos ofertantes, os quais seriam objeto de debates e 
Docência em Eja no Ifg: Extensão no Contexto da Pandemia Covid19 Josué Vidal Pereira - Sebastião Cláudio Barbosa , et al...

socialização nos encontros síncronos regulares. A sistematização da ementa do minicurso partiu do pressuposto da educação como parte da totalidade que é a sociedade capitalista, de modo a desmistificar o papel da escola e da escolarização na sociedade contemporânea, compreendendo a exclusão do acesso à instituição escolar, não como algo natural, mas como elemento inerente à sociedade organizada sob o modo de produção capitalista. Para tanto foram discutidos textos, que, em sua totalidade tratavam do conjunto das questões históricas, políticas, pedagógicas, curriculares e legislação.

\section{Os Encontros Síncronos e Sua Dinâmica Presencial à Dis- tância: A Formação Continuada Possível}

O curso de extensão "Formação Continuada em Docência na 17 EJA" previu o número total de dez encontros síncronos, com duração de duas horas cada, perfazendo um total de 20 horas, sendo que os nove primeiros envolviam leitura e discussão dos textos propostos, ficando o décimo e último encontro com a função de avaliar coletivamente a experiência realizada. Todo o restante do cômputo das 40 horas totais de participação no curso, isto é, 20 horas, ficaram dedicadas assincronamente às leituras, apreciação/ estudo de materiais audiovisuais disponibilizados.

Foi estabelecido como critério de certificação, a participação em pelo menos $70 \%$ dos encontros síncronos. Dos 40 cursistas matriculados, 30 iniciaram as atividades e um total de 19 professores concluíram a Formação Continuada. Em que pese, do ponto de vista estatístico, tal resultado quantitativo parecer pequeno, uma vez que apenas pouco menos da metade conseguiu concluir, consideramos o resultado muito promissor para uma ação desenvolvida no contexto crítico que marca a Pandemia da Covid19. Ade- 
mais deve-se ressaltar as limitações decorrentes de problemas típicos de atividades desenvolvidas via ferramentas de Educação à Distância, tais como questões de infraestrutura e de condições de conexão à Internet, como também aquelas atinentes ao isolamento social, que em muitos casos dificulta a participação do cursista pela dinâmica interna das residências, sobretudo quando se trata de mães que precisam dividir a atenção ao minicurso com cuidados de filhos e demandas de outras ordens.

Desenvolveu-se, como metodologia para cada encontro, uma exposição inicial realizada de forma compartilhada pelos proponentes, destacando as ideias principais contidas em cada texto previsto, assim como seus pontos de vista acerca do contexto sócio, econômico e cultural que os envolvia. Em seguida, abria-se a fala para os integrantes participarem do debate, seja via do chat de texto escrito, seja pela via da exposição oral. Tais participações eram devidamente registradas para fins de avaliação do curso, em que pese o fato de que não foi dada nota com valor numérico pela participação. O critério fundamental para a certificação era a presença na sala e a participação qualitativa na alimentação do debate. Neste momento de alimentação do debate, especialmente, uma vez que os integrantes podiam fazer apartes durante a exposição dos proponentes, cada participante podia expor seu ponto de vista sobre o texto, sua compreensão, assim como um relato de sua experiência com a modalidade EJA e as interfaces possíveis com o texto estudado.

Buscou-se construir uma relação de proximidade nesta dinâmica "presencial à distância". Partiu-se do pressuposto socrático da maiêutica, no sentido de, por meio do diálogo fazer o "parto das ideias". Significa dizer que, em que pese os proponentes assumirem a ministração do curso, o compartilhamento de ideias e a construção do conhecimento como equidistante, foi a tônica do 
Docência em Eja no Ifg: Extensão no Contexto da Pandemia Covid19 Josué Vidal Pereira - Sebastião Cláudio Barbosa , et al...

funcionamento do curso. Intencionalmente, buscamos combater o "eu sei/você não sabe" na prática. Esse intento parece ter sido alcançado, uma vez que os relatos dos participantes ao final do curso foram muito carinhosos e elogiosos. Um exemplo, foi um comentário de uma participante (KCO) que, ao final, disse: "gostei muito do Josué, do Tião, da participação dos colegas... Eu fico feliz pelo fato dos debates que aconteceram. Porque não é só o teórico, né, [dos textos], eu preciso do teórico para me acompanhar no contexto da sala de aula... Talvez, eu não saia desse curso com toda a bagagem, mas, saio sabendo procurar". Outra participante (NNO) acrescentou que "é muito bom participar de cursos como esse... pessoas interessadas e um material muito rico. Na EJA você tem que ser mais que um professor... Precisa criar vínculos com a realidade do educando. E esse curso esclareceu muito a minha cabeça nesse aspecto". A participante (RB) mencionou que "a EJA precisa desses momentos de formação, que não pode parar aqui". O participante (RBJ) apontou que ele se aproximou da EJA pelos cursos livres que fez na UFG e que "não adianta ser doutor... $\mathrm{Na}$ EJA tem que ser doutor em EJA, tem que ter formação continuada, entender as especificidades dessa modalidade. Esse nosso curso é um início pra outras referências. Os textos do curso eu imprimi e vou guardá-los com muito carinho. Foram ótimos momentos".

Fica claro que os carinhos e elogios não foram dirigidos, necessariamente, à possível "sabedoria e/ou didática dos proponentes". Eles foram dirigidos ao curso, aos momentos propiciados coletivamente. Um elogio à participação, enfim. Foram momentos muito curtidos por quem participou e que deixou um desejo de reedição em momentos futuros. Demanda para tal intento não falta! 


\title{
Considerações finais
}

A experiência relatada neste texto tratou de uma importante ação de extensão de uma Instituição pública e gratuita federal, o IFG, cujo papel social é articular ensino, pesquisa e extensão em vista do atendimento das demandas do desenvolvimento socioeconômico local e regional. É o que prevê o Plano de Desenvolvimento Institucional - PDI do Instituto Federal de Goiás 2019 2023, na sua meta 38:

\begin{abstract}
Ofertar capacitação técnica pedagógica aos profissionais da educação das redes públicas de ensino por meio de: a) diálogo e parcerias permanentes com as diferentes redes de ensino; b) projetos de extensão; c) programas e projetos de iniciação à docência; d) parcerias entre Instituto Federal de Educação, Ciência e Tecnologia de Goiás e as escolas campo de estágio das licenciaturas; dentre outros. (Instituto Federal de Goiás, 2019).
\end{abstract}

Conforme se pontuou neste trabalho, as demandas por formação inicial e continuada no âmbito da modalidade de Educação de Jovens e Adultos são demasiadamente desafiadoras em termos quantitativos. Verificou-se que as ações de extensão se constituem em grande potencializador da formação continuada, sobretudo, dada a flexibilidade de tempo-espaço e recursos, tanto do ponto de vista dos ofertantes quanto do público-alvo.

No atual e dramático contexto, marcado por grandes recuos das políticas educacionais, tanto no que tange aos aspecto do financiamento - determinado pelas políticas de arrocho fiscal de longo prazo, e não menos grave, pelo aparelhamento político-ideológico de órgãos ligados às áreas de educação e cultura, como também pela extinção de outros departamentos encarregados de 
políticas de inclusão e pela supressão da participação das representações populares nos órgãos colegiados da área, as ações de extensão desta natureza se constituem como práticas de resistência e de enfrentamento ao que claramente pode ser denominado como Estado de exceção.

Parafraseando Guimarães Rosa, ações contra hegemônicas de cunho emancipatório são veredas de um grande sertão a ser desbravado: o sertão da ignorância, do senso comum e do obscurantismo. Embora saibamos dos limites impostos pela conjuntura do Estado autoritário ultra neoliberal, temos clareza que a formação continuada dos educadores pode resultar em mudanças de atitudes no fazer docente que trarão impactos imediatos e mediatos na qualidade da formação da escola pública.

Paulo Freire em sua Pedagogia da Autonomia (2004), nos alertava a todos acerca do risco do imobilismo em face do ambiente de domínio do espírito neoliberal, que, por meio da ideologia pós-moderna tratava (e continua a fazê-lo) de naturalizar o fenômeno da exclusão social na sociedade atual, impondo-a como inexorável. De modo que adaptados ao pragmatismo neoliberal, só teríamos uma saída, ou seja, o submetimento: “(...) adaptar o educando a esta realidade que não pode ser mudada". Desse ponto de vista neotecnicista, denuncia Freire, "o que se precisa, por isso mesmo, é o treino técnico indispensável à adaptação do educando, à sua sobrevivência" (p. 12). Mas, contra o "chicote" da hegemonia, a contra hegemonia está atuando e construindo um outro mundo possível, quiçá, sem "chicotes".

Entendemos, concordando substantivamente com Paulo Freire, a necessidade do combate a tal imobilismo, e reafirmamos a importância do desenvolvimento de ações, que mesmo aparentemente singelas, se constituem em práxis, que sinalizam o esperançar da necessária ruptura com a ordem desumanizadora que, 
Docência em Eja no Ifg: Extensão no Contexto da Pandemia Covid19 Josué Vidal Pereira - Sebastião Cláudio Barbosa , et al...

por meio da educação, busca o adestramento do humano e sua consequente subsunção à lógica de uma sociedade de produção de mercadorias, na qual o próprio trabalhador é ele mesmo coisificado. O compromisso ético-político do educador popular exige um mover-se no sentido contracorrente, no sentido da ruptura com vistas à emancipação dos trabalhadores da educação e dos educandos Adolescentes, Jovens e Adultos Trabalhadores.

\section{Referências}

BAUER, Adriana. Do diREITO À EDUCAÇÃo À NOÇão do QUASE-MERCADO: tensões na política de educação básica bRasileira. Revista Brasileira de Política e Administração da Educação - Periódico científico editado pela ANPAE, [S.L.], v. 24, N. 3, MAR. 2011. ISSN 2447-4193. DiSPONÍVEL EM: HTTPS://WWW.SEER.UFRGS.BR/RBPAE/ARTICLE/VIEW/19272. ACESSO EM: 12 OUT. 2020. DOI: HTTPS://DOI.ORG/10.21573/VOL24N32008.19272.

BRASil. Congresso Nacional. Lei Federal nº 9.394. Lei de Diretrizes e Bases da Educação Nacional. 20 de dezembro de 1996.

Decreto n. 5.840. Integração da Educação Profissional com a Educação Básica na Modalidade de Educação de Jovens e Adultos - PROEjA. BRASÍLIA, DF, 2006. DisPONÍVEL EM: HTTP://WwW.PLANALTO.GOV.BR/CCIVIL_03/_ ATO2004-2006/2006/DECRETO/D5840.hTM. ACESSO EM: 12 JUN. 2020. - Instituto Nacional de Estudos e Pesquisas Educacionais Anísio Teixeira. Ministério da Educação. Censo escolar da educação básica 2008. BRASÍLIA, DF: INEP/MEC, 2009. - Instituto Nacional de Estudos e Pesquisas Educacionais Anísio Teixeira. Ministério da Educação. Censo escolar da educaÇão básica 2013. BrAsílIA, DF: INEP/MEC, 2014. . Instituto Nacional de Estudos e Pesquisas Educacionais Anísio 
Docência em Eja no Ifg: Extensão no Contexto da Pandemia Covid19 Josué Vidal Pereira • Sebastião Cláudio Barbosa , et al...

Teixeira. Ministério da Educação. Censo escolar da educação básica 2018. BrasílIA, DF: INEP/MEC, 2019.

Lei No 11.494 (2007). Regulamenta o Fundo de Manutenção e Desenvolvimento da Educação Básica e de Valorização dos Profissionais da EducaÇão - FUNDEB. WwW.Planalto.gov.br, Acesso em 18 de Ago 2020. MEC. Conselho Nacional de Educação/Câmara da Educação Básica. Reexame do Parecer CNE/CeB nº 23/2008, que institui Diretrizes Operacionais para a Educação de Jovens e Adultos - Eja. Brasília, 07 MAR. 2010. DisponívEL EM: HTTP://WWW.CEEPI.PRO.BR/NORMA\%20CNE\%20 MEC/2010\%20Res\%20CNE\%20CEB\%2006\%20-\%20NovAs\%20DIRETRIZES\%20operacionais\%20para\%20EF\%209\%20anos.pdF. Acesso em: 12 OUT. 2020.

Bueno, Ederson Nunes; PERGHer, Calinca Jordânia. Analisando a Trajetória dos Fatores de Ponderação Estabelecidos no FUNDEB: 20072016. FineduCA - Revista de Financiamento da Educação, [S.l.], v. 7, MAIO 2017. ISSN 2236-5907. DISPONÍVEL EM: HTTPS://SEER.UFRGS.BR/ FINEDUCA/ARTICLE/VIEW/69472. AcESSO EM: 03 Nov. 2020. DOI:HTTPS://DOI. ORG/10.17648/FINEDUCA-2236-5907-V7-69472.

CARVAlho, Cristina Helena Almeida de. A mercantilização da educação SUPERIOR BRASILEIRA E AS ESTRATÉGIAS DE MERCADO DAS INSTITUIÇÕES LUCRATIVAS. Rev. Bras. Educ., Rio de Janeiro, v. 18, N. 54, P. 761-776, 2013. DISPONÍVEL EM: HTTP://WWW.SCIELO.BR/SCIELO.PHP?SCRIPT=SCI_ARTTEX$T \& P I D=S 1413-24782013000300013 \& L N G=E N \& N R M=I S O$. ACESSO EM: 03 NOV. 2020. HTTP://DX.DOI.ORG/10.1590/S1413-24782013000300013.

Freire, Paulo . Pedagogia da autonomia: saberes necessários a prática educativa. São Paulo: Paz e Terra, 2004.

FREITAS, LUIZ CARLOS DE. OS REFORMAdORES EMPRESARIAIS DA EDUCAÇÃO: DA DESMORALIZAÇÃO DO MAGISTÉRIO À DESTRUIÇÃO DO SISTEMA PÚBLICO DE EDUCAÇÃO. 
Docência em Eja no Ifg: Extensão no Contexto da Pandemia Covid19 Josué Vidal Pereira - Sebastião Cláudio Barbosa , et al...

Revista Educação \& Sociedade, vol. 33, núm. 119, ABRIL-Junho, 2012, PP. 379-404. Centro de Estudos Educação e Sociedade, Campinas, Brasil. DisPONÍVEL EM: HTTP://CEDES.UNICAMP.BR. ACESSO EM: 03 NOV. 2020.

GENTILI, P. EduCAR PARA O DESEMPREGO: A DESINTEGRAÇÃo DA PROMESSA INTEGRAdora. In: FRIGOTTO, G. (ORG.). EducaÇÃo E CRISE dO trabalho: perspectivas de final de século. 4. Ed. Petrópolis: Vozes, 1998. (Coleção Estudos Culturais em Educação). P. 76-99

instituto federal de GoiÁs. Plano de Desenvolvimento InstitucioNAL 2019 -2023. DISPONÍVEL EM HTTPS://WWW.IFG.EDU.BR/ATTACHMENTS/ARTICLE/11546/PDI_IFG_2019_2023.PDF. ACESSO EM: 20 OUT. 2020.

MARX, Karl, ENGELS, F. Manifesto Comunista. Versão eletrônica para E-book. Disponível em: www.ebooksbrasil.com. Acesso em: 20 malo 2020. Pereira. Josué Vidal. O Proeja no IFG Campus Goiânia: fatores de acesso e PermanênCia na escola. 2011. DissertaÇÃo (Mestrado) - UnB, Brasília, 2011. DISPONÍVEL EM: HTTPS://REPOSITORIO.UNB.BR/BITSTREAM/10482/9311/1/2011_JOSUeVidalPereira.PDF . Acesso em: 12 out. 2020.

RUMMERT, Sonia Maria (2007). A Educação de Jovens e Adultos traBalHadores brasileiros no sÉculo XXI. O “NOVo" QUe ReItera antiga destituição de diReitos. Sísıfo. ReVISTA de CiênCIAS da EduCaÇão, Nº 2, PP. 35-50. DisPONÍVEL EM: HTTP://FORUMEJA.ORG.BR/SITES/FORUMEJA.ORG.BR/FILES/ SISIFO0203_RUMMERT.PDF. ACESSO EM: 01 OUT. 2020.

Ventura, Jaqueline P. Educação de Jovens e Adultos Trabalhadores no Brasil: ReVendo alguns marcos históricos. Niteról: PÁGINA EletrônicA. DisPonível EM: HTTP://WWW.UfF.BR/EJATRABALHADORES, 2006 (ARTIGO - PÁGINA Web). Acesso em: 01 out. 2020. 